each other, we can calculate the selectivity coefficients for the ion exchange reactions strontium-calcium and strontium-magnesium from the results given in Table 1 .

The selectivity coefficient is defined by the equation

$$
k_{M e_{\mathrm{II}}}^{M e_{\mathrm{I}}}=\frac{\left[M e_{\mathrm{I}}\right]_{a} \cdot\left[M e_{\mathrm{II}}\right]_{w}}{\left[M e_{\mathrm{II}}\right]_{a} \cdot\left[M e_{\mathrm{I}}\right]_{w}}
$$

where subscripts $a$ and $w$ refer to algae and sea water respectively and the figures within the brackets refer to the concentration of the ions. It has been shown ${ }^{8,9}$ that the activity coefficients for calcium and magnesium ions in sea water are about equal, and, assuming the same activity coefficient also for strontium ions, the ratio between the ion concentrations should be approximately equal to the ratio between the activities of the ions.

In Fig. 1 the resulting selectivity coefficients are shown as a function of the uronic acid composition of the alginates. The curves represent the results obtained from laboratory experiments with pure alginates. The agreement between the results obtained for pure alginates in salt solutions and for brown algae living in their natural environment is remarkably good. A complete agreement should not be expected, because the experiments with alginates are carried out in conditions where approximately equal amounts of the two ions are bound to the polymer; and previous results have shown that the selectivity coefficients show some dependence on the ratio of the two cations bound to the alginate ${ }^{10}$. The results therefore indicate that the content of the divalent metals calcium, magnesium and strontium in brown algae to a large extent is determined by the ion exchange taking place between the sea water and the alginate in the plants.

Norwegian Institute of Seaweed Research,

Arne Haug

OLAV SMIDSRøD

Trondheim.

Received June 26, 1967.

${ }^{1}$ Paul, T. M., Waldron-Edward, D., and Skoryna, S. L., Canad. Med. Assoc. J., 91, 553 (1964).

${ }^{2}$ Hesp, R., and Ramsbottom, B., Nature, 208, 1341 (1965).

${ }^{3}$ Harrison, G. E., Fumphreys, E. R., Sutton, A., and Shepherd, H., Science, 152, 655 (1966).

4 Haug, A., and Smidsrød, O., Acta Chem. Scand., 19, 1221 (1965).

' Haug, A., and Smidsrød, O., Nature, 215, 757 (1967).

- Hang, A., Report No. 30 (Norwegian Institute of Seaweed Research, Trondheim, 1964).

'Barnes, H., Apparatus and Methods of Oceanography (George Allen and Unwin, Ltd., London, 1959).

$s$ Thompson, M. E., and Ross, J. W., Science, 154, 1643 (1966).

Thompson, M. E., Science, 153, 866 (1966).

${ }^{10}$ Smidsrod, O., and Haug, A. (to be published).

\section{Side Effects of Dimethyl Sulphoxide}

In view of the increasing interest in the therapeutic value of dimethyl sulphoxide (DMSO) (refs. 1 and 2), we felt that the recent report by Barnett and $\mathrm{Noel}^{3}$ called for some comment. The only important side effect so far reported in animal experiments has been an effect on the lens ${ }^{4,5}$ and it is only as a result of these reports that widespread clinical use of DMSO has been delayed.

Both in the recent paper and the original report, the doses used were far in excess of any possible level which would be considered for clinical practice. Furthermore, the doses given to monkeys were administered by gastric intubation and no systemic use for humans is contemplated at the present time. The highest daily dermal dose so far reported in work with monkeys is $11 \mathrm{~g} / \mathrm{kg}$ (ref. 6). This has been given for up to 6 months without affecting the lens. Extrapolating the reported data from monkey to man would mean that, in order to achieve even slight changes in the lens, a dose of $200 \mathrm{~g} /$ day would be required. At levels such as these the question of impurities becomes important and no mention of the type, source or purity of the product used in these experiments is given by the authors. This omission has been pointed out on a previous occasion ${ }^{7}$ and it is regrettable that this group should continue to overlook these basic data.

DMSO has now been used in quite extensive clinical trials for periods of up to 2 years with only one lens opacity being reported ${ }^{8}$, and in this case the author considered it to be unrelated to DMSO.

It is only because of the exceptionally low general toxicity of DMSO that such massive doses can be administered at all. Indeed, we wonder what other substance with such high physiological activity could be given in the same quantity without producing much more drastie changes in many tissues.

It is important that this ocular side effect should be seen in its proper perspective.

A. D. S. CALDWELl

P. G. T. BYE

Schering Chemicals, Ltd.,

M. H. BRIGGS

Burgess Hill, Sussex.

Received July 3; revised August 1, 1967.

${ }^{1}$ Leake, C. D., Ann. NY Acad Sci.,141, Section 9 (1967).

2 Dimethyl Sulphoxide Symp. (edit. by Laudahn, G., and Gertich, K.) (1966).

${ }^{3}$ Barnett, K. C., and Noel, P. R. B., Nature, 214, 1115 (1967).

‘ Rubin, L. F., and Barnett, K. C., Ann. NY Acad. Sci., 141, 333 (1967).

5 Rubin, L. F., and Mattis, P. A., Science, 153, 83 (1966).

- Smith, E. R., Haddian, Z., and Mason, M. M., Ann. NY Acad. Sci., 141, 96 $(1967)$.

${ }^{7}$ Sacks, L. G., Science, 154, 543 (1966).

${ }^{8}$ Gordon, D. M. (edit. by Laudahn, G., and Gertich, K.), 179, Dimethyl Sulphoxide Symp. (1967).

\section{Invasion of Wheat Roots by Pratylenchus thornei}

SEINHORST developed a model to relate the density of nematodes in a population and the damage caused to plants ${ }^{1}$. Later he developed another model to relate the increase in the population and the density of the population $^{2}$. These models, based on the relationships between predator and prey of Nicholson and Bailey ${ }^{3}$, make two principal assumptions: $(a)$ the "average" nematode is the same at all densities; and $(b)$ the nematodes invade the host tissue randomly, that is they do not attract or repel each other.

The percentage of larvae of Ditylenchus dipsaci that invaded oat seedlings declined as the number of larvae in the inoculum increased 4 . Similar observations were made for Heterodera rostochiensis on potato ${ }^{5}$ and for Meloidogyne incognita on tomato ${ }^{6}$. Larvae of $M$. incognita have been observed directly to enter a root through a single wound made by the first larva to invade. Attraction of larvae was stronger ${ }^{7}$, and invasion more rapid ${ }^{6}$, after the root had been punctured by the first larva. Wallace ${ }^{6}$ suggested six reasons why invasion could be dependent on density and considered that the supporting evidence cast doubt on the validity of Seinhorst's assumption.

Seinhorst" states that the "second assumption could be tested by observing the distribution of nematodes in or on the roots". We have done this for Pratylenchus thornei Sher and Allen in wheat roots and the results cast doubt on the validity of the second assumption. Wheat seedlings were established in sand and, when 4 weeks old, each was inoculated with either 1,500 or $6,000 P$. thornei. Two weeks later, the roots were removed, immersed in Fleming's fixative to stain embedded nematodes ${ }^{8}$, fixed in chromacetic acid overnight, passed through a graded series of alcohols and finally cleared in cedar wood oil.

Fifty pieces of root each $20 \mathrm{~mm}$ long were selected at random from plants inoculated with 1,500 nematodes. Forty-two pieces contained no nematodes, and the other eight contained between one and fifty-three nematodes. Long pieces of root were then selected at random from those containing nematodes, and the number of nematodes in each millimetre was counted with an ocular micrometer (Fig. 1). 